\title{
Characterisation of the triple negative breast cancer phenotype associated with the development of central nervous system metastases
}

\author{
Katerin Rojas Laimito', Angelo Gámez-Pozo ${ }^{2}$, Juan Sepúlveda', Luis Manso', Rocío López-Vacas³, Tomás Pascual'1, \\ Juan A Fresno Vara ${ }^{3}$ and Eva Ciruelos ${ }^{1}$ \\ ${ }^{1}$ Department of Medical Oncology, Hospital 12 de Octubre, Av. de Córdoba, s/n, 28041, Spain \\ 2I+D Department, Biomedica Molecular Medicine, CLAID building, Campus de Cantoblanco, Calle Faraday, 7, Madrid 28049, Spain \\ ${ }^{3}$ Molecular Oncology and Pathology Lab, INGEMM, Hospital La Paz, Spain
}

Correspondence to: Katerin Rojas Laimito. Email: Katerinrojasl@hotmail.com

\section{Abstract}

Aims: Breast cancer $(\mathrm{BC})$ is the most frequent tumour in women, representing $20-30 \%$ of all malignancies, and continues to be the leading cause of cancer deaths among European women. Triple-negative (TN) BC biological aggressiveness is associated with a higher dissemination rate, with central nervous system (CNS) metastases common. This study aims to elucidate the association between gene expression profiles of PTGS2, HBEGF and ST6GALNAC5 and the development of CNS metastases in TNBC.

Methods: This is a case-controlled retrospective study comparing patients (pts) with CNS metastases versus patients without them after adjuvant treatment. The selection of the samples was performed including 30 samples in both case and control groups. Formalin-fixed, paraffin-embedded samples were retrieved from the Hospital 12 de Octubre Biobank. Five $10 \mu \mathrm{m}$ sections from each FFPE sample were deparaffinised with xylene and washed with ethanol, and the RNA was then extracted with the RecoverAll Kit (Ambion). Gene expression was assessed using TaqMan assays.

Results: A total of 53 patients were included in the study. The average age was 55 years (range 25-85). About 47 patients (88.67\%) had ductal histology and presented high grade (III) tumours (40 patients; 75.47\%). Eight women in the case group presented first distant recurrence in the CNS (34.80\%), local recurrence (three patients, 13.04\%), lungs (two patients; $8.7 \%$ ), bone (one patient; $4.34 \%$ ) and other locations (seven patients; 30.38\%). In the control group, first distant recurrence occurred locally (six patients; $46.1 \%$ ), in bone (two patients; $15.4 \%$ ), lungs (one patient; 7.7\%) and other sites (four patients; $23.1 \%$ ). RNA was successfully obtained from 53 out of 60 samples. PTGS2, HBEGF, and ST6GALNAC5 expression values were not related to metastasis location.

Published: $11 / 04 / 2016$

Received: 04/11/2015

ecancer 2016, 10:632 DOI: 10.3332/ecancer.2016.632

Copyright: (C) the authors; licensee ecancermedicalscience. This is an Open Access article distributed under the terms of the Creative Commons Attribution License (http://creativecommons.org/licenses/by/3.0), which permits unrestricted use, distribution, and reproduction in any medium, provided the original work is properly cited. 
Conclusion: TN tumours frequently metastasise to the visceral organs, particularly lungs and brain, and are less common in bone. The literature suggests that expression of the three genes of interest (PTGS2, HBEGF, and ST6GALNAC5) could be different in TNBC patients with CNS metastasis when compared to patients without it. We did not find a differential expression pattern in PTGS2, HBEGF, and ST6GALNAC5 genes in primary TNBC showing CNS metastases. Further studies are needed to clarify the role of these genes in CNS metastases in TNBC patients.

Keywords: breast cancer, central nervous system, metastases, triple negative

\section{Introduction}

The incidence of breast cancer (BC) is increasing [1] and has now displaced cardiovascular pathology as the leading cause of mortality among women in the Western world. In Spain, its incidence, mortality and five-year prevalence are $29 \%, 15 \%$, and $41 \%$, respectively (Globocan 2012), and it is the third most deadly neoplasm in Spain [2, 3] with an annual incidence of 61 cases for every 100,000 women. The triple negative (TN) BC subtype represents approximately $10-20 \%$ of all cases of BC in Caucasian women. It characteristically affects young women, is associated with poor prognosis pathological characteristics, high rates of early tumoural relapse, high rates of visceral metastasis (20-30\%, particularly lung and brain), short survival and the absence of targeted biological therapy. Additionally, it is related to the basal-like group obtained via genetic analysis and to tumours associated with changes in the BRCA1 gene [12-13, 36]. Tumour genetic changes define the conduct of this tumour and could be responsible for the poor prognosis in this type of patient [7]. Recent studies indicate that shorter survival in the group of patients with BC is due to two characteristics: triple-negative (TN) phenotype and central nervous system (CNS) metastasis [6, 19]. A recent study suggests that the differential expression of some genes is related to the appearance of cerebral metastasis [7].

Genetic expression studies based on studies of levels of mRNA such as the PAM50 (RT-PCR) assay [11] have identified at least four molecular subtypes of BC with different clinical behaviour: Luminal A, luminal B, HER2 and basal-like [4]. Correlating this mRNA studybased classification with an immunohistochemical-based classification shows that most tumours that belong to the basal-like subtype lack expression of oestrogen receivers (ER), progesterone receivers and HER-2 and hence are called triple-negative (TN) tumours [5]. Even though tumours that share an aggressive course are grouped together in the TN group, it is not entirely homogenous; there are at least six subgroups of tumours with different gene expression patterns [12].

The only study (BOS and Col.) that has evaluated additional markers related to the development of metastasis at the cerebral level finds that RE-negative BC cells express three genes (PTGS2, HBEGF, and ST6GALNAC5) in an altered form: these cells have a predisposition to spread at the CNS level. In normal physiological conditions, expression of ST6GALNAC5 is only at the cerebral level [38, 39].

In the present work, we will analyse the expression of three genes of interest (PTGS2, HBEGF, and ST6GALNAC5) in the FFPE tissue of primary TN phenotype breast tumours with CNS metastasis compared to patients who do not present with cerebral metastasis.

\section{Materials and methods}

\section{Sample design and selection}

The study is an analytical observational case (30 samples with CNS metastasis) - control (30 samples without CNS metastasis) study, chosen for similar characteristics in each case. The present study was evaluated and approved by the Hospital 12 de Octubre of Madrid's institutional ethics committee.

\section{Patient selection}

Patients diagnosed with BC between January 1, 1994 and December 31, 2012 with clinical information and updated clinical follow-up available in the Hospital 12 of October's archive and documentation service. 


\section{Sample collection}

The selection of the biological samples was taken from the Hospital 12 of October Pathological Anatomy Department's paraffinised tissue bank.

Cases with the TN phenotype with adequate follow-up and with a formalin-fixed and paraffin-embedded (FFPE) tumour sample with at least $50 \%$ tumour cells were selected from the pathological anatomy archive. Subsequently, 30 cases that subsequently metastasised to the CNS and 30 cases that did not were taken.

\section{Sample analysis}

\section{Sample processing}

About 10 micron sections of the FFPE tissue blocks were made using a microtome. The RNA was isolated using the Life Technologies RecoverAll Kit following the manufacturer's protocol. Therefore, the nucleic acids isolated were quantified using UV spectrophotometry.

\section{Gene expression analysis using RT-qPCR}

Quantitative PCR was used to analyse the expression of three genes of interest (PTGS2, HBEGF, and ST6GALNAC5) and two reference genes (IPO8 and POLR2A) validated for use as reference genes for breast cancer using paraffinised tissue [45] using TaqMan assays (ThermoFisher Scientific).

Drawing from the 50-100 ng of RNA extracted from the FFPE samples, a total reverse transcription of 1 ug of RNA was carried out with the Life Technologies High Capacity cDNA Reverse Transcription Kit following the aforementioned company's TaqManGene Expression Assays Protocol.

$\begin{array}{ll}\text { Gene } & \text { Assay ID } \\ \text { IPO8 } & \text { Hs00183533_m1 } \\ \text { POLR2A } & \text { Hs00172187_m1 } \\ \text { PTGS2 } & \text { Hs00153133_m1 } \\ \text { HBEGF } & \text { Hs00181813_m1 } \\ \text { ST6GALNAC5 } & \text { Hs00229612_m1 }\end{array}$

\section{Statistical analysis}

These expression data (Ct values) were obtained in triplicate for each sample, and the mean $\mathrm{Ct}$ was calculated. The missing values were replaced with a maximum $C t$ value set at 40 . Subsequently, the expression values of the genes of interest were standardised using the $\Delta C t$ method, which consists of calculating relative expression values as differences between a normalisation factor, which in this case is the geometric mean of the expression of both reference genes, and the mean CT value of each gene. Later, a constant was added and a relative expression value for each gene in each sample was obtained, in which an increase in one supposes double the expression. In order to evaluate whether there is a differential expression of the genes of interest in TN breast cancer patients with CNS metastasis vis-à-vis the group without CNS metastasis, the Mann-Whitney U-test was applied.

\section{Results}

\section{Clinical characteristics of the patients}

The median age of the patients in the study was 55 years (range 25-85). In this group of patients, 47 (88.67\%) were of the ductal histologic type and 40 patients (75.47\%) were histologic Grade III. Tumour size and nodal involvement are summarised in Table 1. 
Table 1. Clinical characteristics of the tumour.

\begin{tabular}{|c|c|c|}
\hline & Patients (pts) & $\%$ \\
\hline $\boldsymbol{T}_{1}$ & 9 & 16.98 \\
\hline $\boldsymbol{T}_{2}$ & 34 & 64.15 \\
\hline $\boldsymbol{T}_{3}$ & 6 & 11.32 \\
\hline $\boldsymbol{T}_{4}$ & 4 & 7.54 \\
\hline $\boldsymbol{N}_{\mathrm{O}}$ & 20 & 37.73 \\
\hline $\boldsymbol{N}_{1}$ & 13 & 24.52 \\
\hline $\boldsymbol{N}_{2}$ & 6 & 11.32 \\
\hline $\boldsymbol{N}_{3}$ & 14 & 26.41 \\
\hline
\end{tabular}

HBEGF

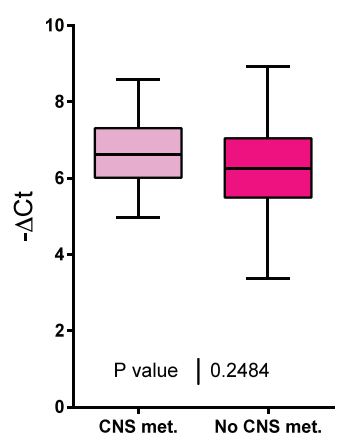

PTGS2

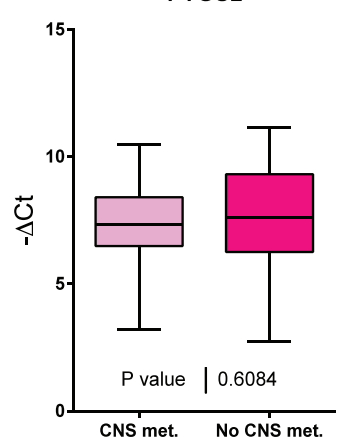

ST6GALNAC5

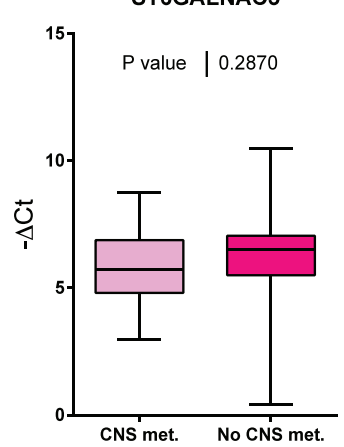

Figure 1. A comparison of HBEGF, PTGS2 and ST6GALNAC5 gene expression in tumour samples from patients with and without CNS metastasis.

In the case group, eight patients (34.80\%) had cerebral metastasis as the first site of recurrence, three patients (13.04\%) had local recurrence, two patients $(8.7 \%)$ lung, one patient $(4.34 \%)$ bone, and seven patients $(30.08 \%)$ other locations. In the control group, six patients $(46.1 \%)$ had local relapse as the first site of remote recurrence, two patients $(15.4 \%)$ bone, one patient $(7.7 \%)$ lung, and four patients $(23.1 \%)$ other sites.

\section{Evaluation of gene expression (PTGS2, HBEGF, ST6GALNAC5)}

Of the 60 selected samples, a sufficient amount of RNA was extracted to carry out experiments on 53 samples. PTGS2, HBEGF, and ST6GALNAC5 gene expression was evaluated for the two groups of interest (Figure 1). No significant differences were found in the expression of these three genes between both groups of patients.

\section{Discussion}

$\mathrm{BC}$, as previously mentioned, is a genetically heterogeneous disease and its clinical incidence, characteristics, and prognosis differ significantly by ethnicity and race [21]. Studies carried out in North America find that Latina patients have a lower incidence but also greater mortality from BC than Caucasian patients. Also, the rate of TN tumours is significantly greater in this group of patients [22-34]. 
The metastasis process is complex and includes cellular intravasation, survival in the circulation, extravasation to a distant organ, angiogenesis and uninhibited growth in the host tissue [8]. Tumour gene expression studies find that the expression of some genes enables tumour cells and predisposes them to dissemination in a specific form to organs like the lungs [9-10].

Exploration of this pathology has begun to produce results and a variety of studies have found responses, albeit modest ones, to drugs like anti-EGFR (cetuximab and erlotinib), SRC inhibitors (dasatinib) and anti-angiogenics (bevacizumab) [14]. Additionally, drugs that target the PI3K/PTEN/AKT pathway and Notch survivin are presently being studied $[14,16,17]$.

The epidemiological evaluation made by our group of the patients with BC seen at the 12 de Octubre University Hospital found that the TN phenotype, in concurrence with the American reports, represents around $20 \%$ of breast tumours [22].

The development of cerebral metastasis differs from that of other locations due to particularities like the special composition and density of the cerebral parenchyma and the high impermeability of the blood-brain barrier (BBB) produced by the complexity of the structures that form it, including tight junctions, the absence of fenestrations and very low pinocytic activity, as well as an extracellular matrix, pericytes, and astrocytic foot processes. The cerebral capillaries also have a high electrical resistance that increases the impermeability of this membrane to the polar and ionic substrata. Added to this is a set of extraction transporters that includes $p$-glycoprotein, MRP-1 to 6 , breast cancer-resistant protein (BCRP), and organic anion and cation transporters [20]. All this causes systemic therapies to pass through the BBB, and therefore, their access to metastasised parts of the brain is low and insufficient to guarantee the effectiveness of most of the treatments available.

Bos et al selected RE-negative BC cells with a high predisposition to infiltrate the brain and evaluated the expression of more than 240 genes in them. The process included the inoculation of these cells in murine models, and the selection of those cells with high capacity to develop cerebral metastasis. After identifying genes through an in vivo model, their role was evaluated on the basis of breast tumour data and a group of genes related to the development of cerebral metastasis in RE-negative breast tumours was thus selected. They found that the altered expression of 17 genes was associated with the development of cerebral metastasis. Three of these genes had high expression: cyclooxygenase COX2, an EGFR ligand and the a2, 6-sialyltransferase ST6GALNAC5 gene. The identification of the COX2 gene in this group demonstrates the importance of the inflammation process in the development of brain metastasis, whereas genes related to the epithelial growth factor (EGF) are related to the replication capacity of the tumour cell. Finally, sialyltransferases are related to cell-cell interactions and change in this capacity could be related to the capacity to produce remote metastasis [7].

TN tumours frequently metastasise to the visceral organs, particularly the lungs and brain, and less frequently at the bone level. The literature suggests that the expression of the three genes of interest (PTGS2, HBEGF, and ST6GALNAC5) must be different in patients with TNBC that developed metastasis at the cerebral level when compared to patients who do not develop CNS metastasis.

We did not find a differential expression pattern in these genes (PTGS2, HBEGF, ST6GALNAC5) in the primary breast tumour that developed cerebral metastasis. This could be due to the fact that cerebral metastases host genetic alterations different from the ones observed in the primary tumours; this is still unknown. Priscilla et al sequenced the exome of 86 cerebral metastases paired with the primary tumour tissue and normal tissue, finding clinically informative changes in the cerebral metastasis that were not found in the primary tumour tissue sample in $53 \%$ of the cases. The genes involved in the development of cerebral metastasis with greater frequency were TP53, PIK3CA, GATA3 and other mutated genes in lesser frequency including AKT1, CDH1, MAP3K1, PTEN, CDH1, RB1, and CDKN1B. They concluded that activation of the PI3K/AKT/mTOR pathway and CDK may be involved in the development of CNS metastasis [40].

The study of patients with TNBC who carry the BRCA-1 and BRCA-2 mutation is one analysis pathway, as these tumours are sensitive to PARP (polyadenosine diphosphate ribose polymerase 1) inhibitors like Olaparib, which penetrates the BBB [15, 44].

Other authors have suggested that androgens, directly activating astrocytes in the cerebral microenvironment, can facilitate the establishment of neoplastic cells originating in TN breast tumours. This would explain why younger TN patients, with greater oestrogen levels, have a greater risk of cerebral metastasis [41]. These findings could justify the absence of differences in gene expression between cases with the presence of cerebral metastasis and those that do not develop it, since the development of these metastases will depend more on the hormonal profile of the patient than on intrinsic factors of the tumour cell. 
Other researchers also suggest elements external to the tumour itself as they show that the methylation level is unchanged in TN breast tumour cells in comparison with other BC phenotypes when they metastasise to the brain [42]. Stirzaker et al indicate that characterising methylation patterns could help us identify predictive biomarkers in the future [43].

\section{Conclusion}

In conclusion, our findings highlight that not only are the differences in gene expression important when it comes to predicting the risk of cerebral metastasis but also other aspects like oestrogen level could play an important role. Future studies are needed to clarify the role of these genes in primary breast tumours in patients with TNBC who develop cerebral metastases.

\section{References}

1. Smigal C, Jemal A and Ward E et al (2006) Trends in breast cancer by race and ethnicity: update 2006 CA Cancer J Clin 56 168-183 DOI: $\underline{10.3322 / \text { canjclin.56.3.168 PMID: } 16737949}$

2. Ferlay J, Soerjomataram I and Ervik M et al (2012) Incidencia y mortalidad para todas las edades Prevalencia a 5 años sólo en población adulta GLOBOCAN 2012 v1.0, Cancer Incidence and Mortality Worldwide: IARC

3. Bray F, Ren JS and Masuyer E et al (2013) Estimates of global cancer prevalence for $\mathbf{2 7}$ sites in the adult population in 2008 Int J Cancer 132(5) 1133-1145 DOI: 10.1002/ijc.27711 Epub 2012 Jul 26

4. Sorlie T, Perou CM and Tibshirani R et al (2001) Gene expression patterns of breast carcinomas distinguish tumor subclasses with clinical implications Proc Natl Acad Sci U S A 98 10869-10874 DOI: 10.1073/pnas.191367098 PMID: 11553815 PMCID: $\underline{58566}$

5. Carey LA, Perou CM and Livasy CA et al (2006) Race, breast cancer subtypes, and survival in the Carolina breast cancer study JAMA 295 2492-2502 DOI: 10.1001/jama.295.21.2492 PMID: 16757721

6. Niwinska A, Murawska M and Pogoda K (2010) Breast cancer brain metastases: differences in survival depending on biological subtype, RPA RTOG prognostic class and systemic treatment after whole-brain radiotherapy (WBRT) Ann Oncol 21 942-948

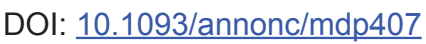

7. Bos PD, Zhang XH and Nadal C et al (2009) Genes that mediate breast cancer metastasis to the brain Nature 459 1005-1009 DOI: 10.1038/nature08021 PMID: 19421193 PMCID: 2698953

8. Chambers AF, Groom AC and MacDonald IC (2002) Dissemination and growth of cancer cells in metastatic sites Nat Rev Cancer 2 563-572 DOI: $10.1038 / n r c 865$ PMID: 12154349

9. Castaneda CA, Agullo-Ortuno MT and Fresno Vara JA et al (2011) Implication of miRNA in the diagnosis and treatment of breast cancer Expert Rev Anticancer Ther 11 1265-1275 DOI: 10.1586/era.11.40 PMID: 21916580

10. Minn AJ, Gupta GP and Siegel PM et al (2005) Genes that mediate breast cancer metastasis to lung Nature $436518-524$ DOI: 10.1038/nature03799 PMID: 16049480 PMCID: 1283098

11. Parker JS, Mullins $M$ and Cheang MC et al (2009) Supervised risk predictor of breast cancer based on intrinsic subtypes $J$ Clin Oncol 27 1160-1167 DOI: 10.1200/JCO.2008.18.1370 PMID: 19204204 PMCID: 2667820

12. Lehmann BD, Bauer JA and Chen $X$ et al (2011) Identification of human triple-negative breast cancer subtypes and preclinical models for selection of targeted therapies J Clin Invest 121 2750-2767 DOI: 10.1172/JCI45014 PMID: 21633166 PMCID: $\underline{3127435}$ 
13. Lachapelle J and Foulkes WD (2011) Triple-negative and basal-like breast cancer: implications for oncologists Curr Oncol 18 161-164 DOI: 10.3747/co.v18i4.824 PMID: 21874112 PMCID: 3149541

14. Reddy KB (2011) Triple-negative breast cancers: an updated review on treatment options Curr Oncol 18:e173-e179 DOI: 10.3747/co.v18i4.738 PMID: 21874107 PMCID: $\underline{3149549}$

15. O'Shaughnessy J, Osborne $C$ and Pippen JE et al (2011) Iniparib plus chemotherapy in metastatic triple-negative breast cancer N Engl J Med 364 205-214 DOI: 10.1056/NEJMoa1011418

16. Castaneda CA, Cortes-Funes $\mathrm{H}$ and Gomez HL et al (2010) The phosphatidyl inositol 3-kinase/AKT signaling pathway in breast cancer Cancer Metastasis Rev 29 751-759 DOI: 10.1007/s10555-010-9261-0 PMID: 20922461

17. National Cancer Institute (Access to Investigational Drugs) www.cancer.gov/about-cancer/treatment/drugs/investigational-drugaccess-fact-sheet

18. Lin NU, Bellon JR and Winer EP (2004) CNS metastases in breast cancer J Clin Oncol 22 3608-3617 DOI: 10.1200/JCO.2004.01.175 PMID: 15337811

19. Nam BH, Kim SY and Han HS et al (2008) Breast cancer subtypes and survival in patients with brain metastases Breast Cancer Res 10 R20 DOI: 10.1186/bcr1870 PMID: 18307763 PMCID: 2374976

20. Deeken JF and Loscher W (2007) The blood-brain barrier and cancer: transporters, treatment, and Trojan horses Clin Cancer Res 13 1663-1674 DOI: 10.1158/1078-0432.CCR-06-2854 PMID: 17363519

21. O'Brien KM, Cole SR and Tse CK et al (2010) Intrinsic breast tumor subtypes, race, and long-term survival in the Carolina breast cancer study Clin Cancer Res 16 6100-6110 DOI: 10.1158/1078-0432.CCR-10-1533

22. Vallejos CS, Gomez HL and Cruz WR et al (2010) Breast cancer classification according to immunohistochemistry markers: subtypes and association with clinicopathologic variables in a peruvian hospital database Clin Breast Cancer 10 294-300 DOI: 10.3816/CBC.2010.n.038 PMID: 20705562

23. Chlebowski RT, Chen $Z$ and Anderson GL et al (2005) Ethnicity and breast cancer: factors influencing differences in incidence and outcome J Natl Cancer Inst 97 439-448 DOI: 10.1093/jnci/dji064 PMID: 15770008

24. Gapstur SM, Dupuis J and Gann P et al (1996) Hormone receptor status of breast tumors in black, Hispanic, and non-Hispanic white women An analysis of 13,239 cases Cancer 77 1465-1471 DOI: 10.1002/(SICI)1097-0142(19960415)77:8\&lt;1465::AIDCNCR7\&gt:3.0.CO:2-B PMID: $\underline{8608530}$

25. Li Cl, Malone KE and Daling JR (2003) Differences in breast cancer stage, treatment, and survival by race and ethnicity Arch Intern Med 163 49-56 DOI: 10.1001/archinte.163.1.49 PMID: $\underline{12523916}$

26. Hausauer AK, Keegan TH and Chang ET et al (2007) Recent breast cancer trends among Asian/Pacific Islander, Hispanic, and African-American women in the US: changes by tumor subtype Breast Cancer Res 9 R90 DOI: 10.1186/bcr1839 PMID: 18162138 PMCID: 2246193

27. Parise CA, Bauer KR and Caggiano V (2010) Variation in breast cancer subtypes with age and race/ethnicity Crit Rev Oncol Hematol 76 44-52 DOI: 10.1016/j.critrevonc.2009.09.002

28. Shavers VL, Harlan LC and Stevens JL (2003) Racial/ethnic variation in clinical presentation, treatment, and survival among breast cancer patients under age 35 Cancer 97 134-147 DOI: $10.1002 / \mathrm{cncr} .11051$

29. Gonzalez Burchard E, Borrell LN and Choudhry $S$ et al (2005) Latino populations: a unique opportunity for the study of race, genetics, and social environment in epidemiological research Am J Public Health 95 2161-2168 DOI: 10.2105/AJPH.2005.068668 PMID: 16257940 PMCID: 1449501 
30. Millikan RC, Newman B and Tse CK et al (2008) Epidemiology of basal-like breast cancer Breast Cancer Res Treat 109 123-139 DOI: 10.1007/s10549-007-9632-6 PMCID: 2443103

31. Pike MC, Kolonel LN and Henderson BE et al (2002) Breast cancer in a multiethnic cohort in Hawaii and Los Angeles: risk factoradjusted incidence in Japanese equals and in Hawaiians exceeds that in Whites Cancer Epidemiol Biomarkers Prev 11 795-800 PMID: 12223421

32. Probst-Hensch NM, Pike MC and McKean-Cowdin R et al (2000) Ethnic differences in post-menopausal plasma oestrogen levels: high oestrone levels in Japanese-American women despite low weight Br J Cancer 82 1867-1870 DOI: 10.1054/bjoc.1999.1082 PMID: 10839304 PMCID: 2363216

33. Looker AC, Dawson-Hughes B and Calvo MS et al (2002) Serum 25-hydroxyvitamin D status of adolescents and adults in two seasonal subpopulations from NHANES III Bone 30 771-777 DOI: 10.1016/S8756-3282(02)00692-0 PMID: 11996918

34. Hsieh MM, Everhart JE and Byrd-Holt DD et al (2007) Prevalence of neutropenia in the U.S. population: age, sex, smoking status, and ethnic differences Ann Intern Med 146 486-492 DOI: 10.7326/0003-4819-146-7-200704030-00004 PMID: 17404350

35. Castaneda CA GH, Vallejos C and Cortes-Funes et al (2011) Comparison between Spanish and Peruvian Patients with early breast cancer In: San Antonio Breast Cancer Meeting

36. Heitz F, Harter P and Lueck HJ et al (2009) Triple-negative and HER2-overexpressing breast cancer exhibit an elevated risk and an earlier occurrence of cerebral metastases Eur J Cancer 45 2792-2798 DOI: 10.1016/j.ejca.2009.06.027 PMID: 19643597

37. Foulkes WD, Smith IE and Reis-Filho JS Triple-negative breast cancer N England 363 1938-1948

38. Don X, Nguyen, Paula D Bos and Joan Massagué (2009) Metastasis: from dissemination to organ-specific colonization Nature Rev Cancer 9 274-284 DOI: $10.1038 / n r c 2622$

39. Bollig-Fischer A, Michelhaugh SK and Ali-Fehmi R et al (2013) The molecular genomics of metastatic brain tumours OA Mol Oncol 1(1) 6

40. Brastianos PK, Carter SL and Santagata S et al (2015) Genomic characterization of brain metastases reveals branched evolution and potencial therapeutic targets Cancer Discov 5(11) 1-14 DOI: $10.1158 / 2159-8290 . C D-15-0369$

41. Sartorius CA, Hanna CT and Grill B et al (2015) Estrogen promotes the brain metastatic colonization of triple negative breast cancer cells via an astrocyte-mediated paracrine mechanism Oncogene 28 1-12 DOI:10.1038/onc.2015.353 PMID: 26411365

42. Salhia B, Kiefer $\mathrm{J}$ and Ross JT et al (2014) Integrated genomic and epigenomic analysis of breast cancer brain metastasis PLoS One 9 e85448 DOI: 10.1371/journal.pone.0085448 PMID: 24489661 PMCID: 3906004

43. Stirzaker C, Zotenko E and Song JZ et al (2015) Methylome sequencing in triple-negative breast cancer reveals distinct methylation clusters with prognostic value Nat Commun 65899 DOI: 10.1038/ncomms6899 PMID: 25641231

44. Chalmers AJ (2010) Overcoming resistance of Glioblastoma to conventional cytotoxic therapies by the addition of PARP inhibitors Anticancer Agents Med Chem 10 520-533 DOI: 10.2174/187152010793498627 PMID: 20879987

45. Sánchez-Navarro I, Gámez-Pozo A and González-Barón M et al (2010) Comparison of gene expression profiling by reverse transcription quantitative PCR between fresh frozen and formalin-fixed, paraffin-embedded breast cancer tissues Biotechniques 48(5) 389-97 DOI: $\underline{10.2144 / 000113388}$ 